\title{
COMPARAÇÃO DE TRÊS RECEPTORES GPS PARA USO EM AGRICULTURA DE PRECISÃO
}

\author{
MARCELO C. C. STABILE ${ }^{1}$, LUIZ A. BALASTREIRE ${ }^{2}$
}

RESUMO: Diversos equipamentos que se utilizam dos sinais transmitidos pelo Sistema de Posicionamento Global (GPS) têm sido empregados na Agricultura de Precisão. Neste estudo, foi feita uma comparação de três receptores comerciais no intuito de verificar suas acurácias. As principais qualidades medidas foram a repetibilidade dos dados e a estabilidade do sistema. $\mathrm{O}$ estudo foi conduzido em campo aberto, na área experimental da ESALQ/USP, com três linhas paralelas de $50 \mathrm{~m}$ espaçadas $10 \mathrm{~m}$ entre si. A coleta de dados foi feita no dia 25-9-2002, totalizando seis repetições da comparação dos três sistemas. Os dados foram coletados simultaneamente, de acordo com a melhor configuração da constelação de satélites, sendo que os três sistemas apresentaram resultados distintos. O GPS "A" (oito canais, sem correção diferencial) apresentou a maior variabilidade e a menor repetibilidade, com desvios de quase 10 m numa mesma linha. O sistema "B", com sinal de correção diferencial (DGPS “B”, 12 canais), apresentou acurácia superior ao "A”, com desvios de, no máximo, $6 \mathrm{~m}$, mas com repetibilidade significativa. O GPS " $\mathrm{C}$ " (12 canais, com algoritmo otimizado) apresentou a maior acurácia e desvio máximo de $2 \mathrm{~m}$. Assim, os dois últimos sistemas são adequados para a aplicação dos conceitos da Agricultura de Precisão.

PALAVRAS-CHAVE: agricultura de precisão, GPS, precisão de posicionamento.

\section{COMPARISON OF THREE GPS RECEIVER FOR PRECISION AGRICULTURE USES}

ABSTRACT: Several brands of equipment have been used with global positioning systems (GPS) in Precision Agriculture. The quality of these different receivers varies according to their capabilities in terms of accuracy and repeatability. In this study, three commercial systems were tested to compare their accuracies. This study focused on measuring the stability of the receiver and the repeatability of data. The study was conducted in the experimental area of ESALQ/USP. It consisted of three parallel 50-meter lines spaced 10 meters apart. Data collection was done on 9-25-2002 with a total of six replications. Data was collected simultaneously and the date and time of data collection were chosen to minimize the physical dilution of precision (PDOP). The three receivers had quite different performance. The GPS " $A$ " (8-channel) had the highest variability and the lowest repeatability of data. The differential GPS (DGPS) "B" (12-channel) had higher accuracy, with a maximum deviation of $6 \mathrm{~m}$, but with significant repeatability. The GPS "C" with optimized algorithm had the highest accuracy and deviations no greater than 2m. Both GPS's "B" and "C" are adequate for Precision Agriculture uses.

KEYWORDS: precision agriculture, GPS, positioning accuracy.

\section{INTRODUÇÃO}

Segundo MORGAN (1997), o sistema de posicionamento global (GPS) foi criado pelo governo dos Estados Unidos com o objetivo principal de localizar suas tropas em qualquer lugar da terra. É

\footnotetext{
${ }^{1}$ Eng ${ }^{0}$ Agrônomo, Mestre em Agronomia, Department of Soil \& Crop Sciences, Texas A\&M University, College Station, Fone: +1 979 676.0033, mccstabile@ hotmail.com

${ }^{2}$ Eng ${ }^{\mathrm{O}}$ Agrônomo, Professor Titular Aposentado, Departamento de Engenharia Rural, ESALQ/USP, Piracicaba - SP.

Recebido pelo Conselho Editorial em: 21-3-2005

Aprovado pelo Conselho Editorial em: 13-4-2006
} 
constituído de 24 satélites, dos quais 21 são de uso corrente e três em "stand-by". Eles orbitam a uma altura de $20.200 \mathrm{~km}$ em seis órbitas distintas, igualmente espaçadas de 60 graus, com quatro satélites por órbita. Os sinais são emitidos em duas bandas (L1 e L2) com dois códigos diferentes: o Y (Precision code) e o C/A (Coarse Acquisition code); assim sendo, o sistema teoricamente permite uma visão de cinco a oito satélites constantemente, em qualquer lugar do globo (CASTRO, 2004).

De acordo com SEARCY (2001), o Departamento de Defesa dos Estados Unidos (DoD) restringiu o uso do código de precisão (Y) aos militares, que é criptografado, e até maio de 2000 utilizava um sistema de disponibilidade seletiva (S/A) para reduzir a acurácia dos sinais, deixando-a em torno de 60 a $100 \mathrm{~m}$. Dessa inacurácia, $60 \%$ provém do S/A, 20\% são erros atmosféricos, $10 \%$ são erros de relógio e erros efêmeros, $5 \%$ de multicaminhamento e $5 \%$ de "ruído" no receptor. Visando a contornar alguns desses problemas, incluindo o do S/A, foi desenvolvido o sistema de posicionamento diferencial e relativo (DGPS).

Segundo PFOST et al. (2001), o DGPS utiliza um sinal de correção emitido por uma estação fixa, seja ela uma antena fixa na terra, seja um satélite estacionário. Como a sua posição no globo terrestre é conhecida, a estação calcula e determina o erro de posição, enviando o sinal de correção em tempo real para os receptores GPS.

O uso de GPS na agricultura possibilita uma abordagem localizada dos problemas dentro da propriedade rural. $\mathrm{O}$ alto custo de aquisição e uso dessas ferramentas tem detido um pleno avanço da Agricultura de Precisão no Brasil. Para que se possa usar um GPS para fins de Agricultura de Precisão, é necessário que esse tenha acurácia de, no mínimo, $2 \mathrm{~m}$, sendo essa suficiente para a maioria das aplicações; em algumas aplicações agrícolas, pode ser necessária acurácia maior. A grande variabilidade de solos e condições num mesmo talhão da fazenda é tratada diferentemente e, para tanto, é necessário que o GPS produza dados confiáveis e consistentes (BALASTREIRE, 2001).

Segundo BLITZKOW (1995), o sistema GPS-NAVSTAR ("Navigation Satelite Time and Ranging”) foi desenvolvido pelo Departamento de Defesa dos Estados Unidos da América. Trata-se de um sistema militar estratégico com enorme potencial para as aplicações civis. O setor civil passou a ter acesso a essa tecnologia a partir de meados da década de 1970 e tornou-se inteiramente operacional em 1993, quando universidades e instituições de pesquisa puderam, então, investigar e, inclusive, colaborar no aperfeiçoamento do sistema.

GOERING \& HAN (1993) afirmaram que um dos problemas para a execução das atividades relacionadas com a Agricultura de Precisão referia-se às limitações dos sistemas terrestres de navegação. Um sistema de navegação via satélite, denominado Sistema de Posicionamento Global ("Global Positioning System - GPS"), representava a mais promissora solução para o problema da navegação, à época.

BAIO et al. (1998) citam as principais fontes de erros para o posicionamento, ao se utilizar do sistema GPS: a disposição geométrica dos satélites, o efeito do multicaminhamento, o erro do relógio do receptor GPS, a interferência da ionosfera e o erro orbital do satélite. Afirmam, ainda, que a acurácia do sistema depende de vários fatores, dentre eles: configuração do sistema GPS no momento do posicionamento; frequência do sinal GPS utilizado para o posicionamento (L1, L2 ou C/A); configuração do receptor GPS, como taxa de aquisição, máscara de elevação, etc.; interferência do multicaminhamento no sinal GPS, e o método utilizado para a correção diferencial (satélite, rádio, pósprocessado).

Segundo HAN et al. (1994), para aumentar a acurácia do sistema, pode-se usar uma técnica de correção das posições, denominada correção diferencial. Assim, para o funcionamento do sistema de GPS diferencial ("Differential Global Positioning System - DGPS"), um segundo receptor, denominado receptor ou estação-base, deveria ser instalado em um ponto fixo e de coordenadas 
conhecidas. O erro de posicionamento pode ser estimado por meio da comparação entre os valores calculados pelo receptor fixo de GPS e as coordenadas conhecidas do ponto e pode ser transmitido, via rádio, para o receptor móvel, o qual fará a leitura da correção enviada pela base, e o valor da posição a ser armazenado pode ser, então, previamente corrigido.

A disponibilidade de GPS no mercado é bastante diversificada; os receptores vêm evoluindo a cada dia, minimizando a interferência, melhorando blindagens e reduzindo ruídos. Os preços de GPS variam muito, sendo os mais acessíveis a partir de US\$300,00 e os mais caros podem custar US\$ 40 mil. Essa variação no preço é basicamente devido à tecnologia utilizada no receptor. Há modelos que são propícios para navegação e outros que são utilizados para levantamentos topográficos e que chegam a ter precisão de 2 a $20 \mathrm{~cm}$, como receptores geodésicos, utilizando o posicionamento diferencial (REID, 1998).

No presente estudo, teve-se o objetivo de comparar três receptores disponíveis comercialmente para determinar: a acurácia de cada um dos receptores; quais deles seriam adequados para o uso em Agricultura de Precisão, e a existência de vantagens do uso de um algoritmo otimizado, quando comparado com um DGPS.

\section{MATERIAL E MÉTODOS}

Nesta pesquisa, foram utilizados os seguintes materiais:

- GPS "A" com oito canais, freqüência de aquisição de $1 \mathrm{~Hz}$ e acurácia maior que $25 \mathrm{~m}$ sem disponibilidade seletiva (BALASTREIRE \& BAIO, 2001);

- DGPS “B”, com 12 canais de freqüência de aquisição de dados de $1 \mathrm{~Hz}$, base fixa, rádio transmissor $35 \mathrm{~W}$ para a transmissão do sinal de correção calculado, de acordo com a metodologia descrita por HAN et al. (1994), receptor $2 \mathrm{~W}$ da Pacific Crest e monitor AgNavigator, tendo esse sistema acurácia submétrica;

- GPS “C”, algoritmo otimizado, 12 canais, freqüência de aquisição de dados de $1 \mathrm{~Hz}$, acurácia submétrica, se utilizado com sinal diferencial (BALASTREIRE \& BAIO, 2001);

- Microcomputador AMD Duron $950 \mathrm{MHz}, 512 \mathrm{Mb}$ RAM, $20 \mathrm{~Gb} \mathrm{HD}$, rodando Windows XP Professional, para processamento dos dados;

- 2 PocketPC iPaq 3650, rodando Windows CE para coleta de dados, e

- Trator Massey Ferguson 5285, $46 \mathrm{~kW}(62,5 \mathrm{cv})$, utilizado para a aquisição de dados em condição cinemática, dotado de uma bancada com duas cadeiras acoplada ao sistema de levantamento hidráulico de três pontos do trator, utilizada como suporte dos instrumentos para a coleta dos dados.

Para a comparação dos três receptores comerciais (A, B e C), os testes foram realizados em terreno plano pertencente à ESALQ/USP, em Piracicaba, em campo aberto, sem nenhum obstáculo,

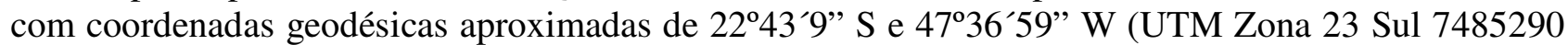
$\mathrm{N}$ e $231252 \mathrm{E})$.

Nessa área, foram marcadas três linhas, espaçadas $10 \mathrm{~m}$ entre si e com $50 \mathrm{~m}$ de comprimento. Os dados foram coletados de forma cinemática, com a bancada de duas cadeiras acoplada ao sistema de levantamento hidráulico de três pontos do trator e, simultaneamente, usando o coletor de dados AgNavigator do DGPS "B", e dois Pocket PC iPaq 3650, sendo um acoplado ao GPS "A" e outro ao GPS "C". O programa utilizado para aquisição de dados, em ambos os Pocket PC, foi o FieldRover II, desenvolvido pela SSTools Development Group. As antenas dos receptores GPS foram agrupadas ao redor do mesmo ponto sobre a cabine do trator, de forma a minimizar qualquer tipo de erro. 
Todos os testes foram conduzidos durante o dia, a partir das $8 \mathrm{~h} 30$ até às $17 \mathrm{~h}$. Para garantir a qualidade do sinal, foi utilizado o programa QuickPlan para planejar a missão, adquirindo-se os almanaques no dia do experimento. O almanaque tem a função de fornecer a posição dos satélites em órbita, e o programa calcula os parâmetros de qualidade do sinal, baseado em sua localização. Os experimentos só foram realizados com o mínimo de seis satélites em vista e com Diluição da Precisão de Posição (PDOP) menor que quatro.

No dia 25 de setembro de 2002, foram feitas seis repetições com os receptores "A", "B" e "C".

Primeiramente, os dados foram transformados em coordenadas planas no sistema de projeção Universal Transverso de Mercator (UTM), para que os desvios fossem calculados em metros. O software Microsoft Excel foi utilizado para fazer os gráficos dos pontos e calcular as regressões das linhas e os desvios das linhas.

\section{RESULTADOS E DISCUSSÃO}

GPS "A"

Os resultados para o sistema de baixo custo GPS "A" estão contidos na Figura 1. O GPS "A" apresentou desempenho mediano, mas bastante inferior aos GPSs "B" e "C". As linhas não aparecem retas. O seu custo inicial é baixo e se contasse com um sinal de correção, uma vez que é "DGPS Ready", teria acurácia bastante superior. Pode-se ver que um GPS comum não é recomendável para uso em Agricultura de Precisão, uma vez que, para conseguir fazer aplicações localizadas, monitorar colheita e aplicar todos os conceitos, são necessárias acurácia e repetibilidade, que só foram conseguidas com os GPSs "B" e "C".

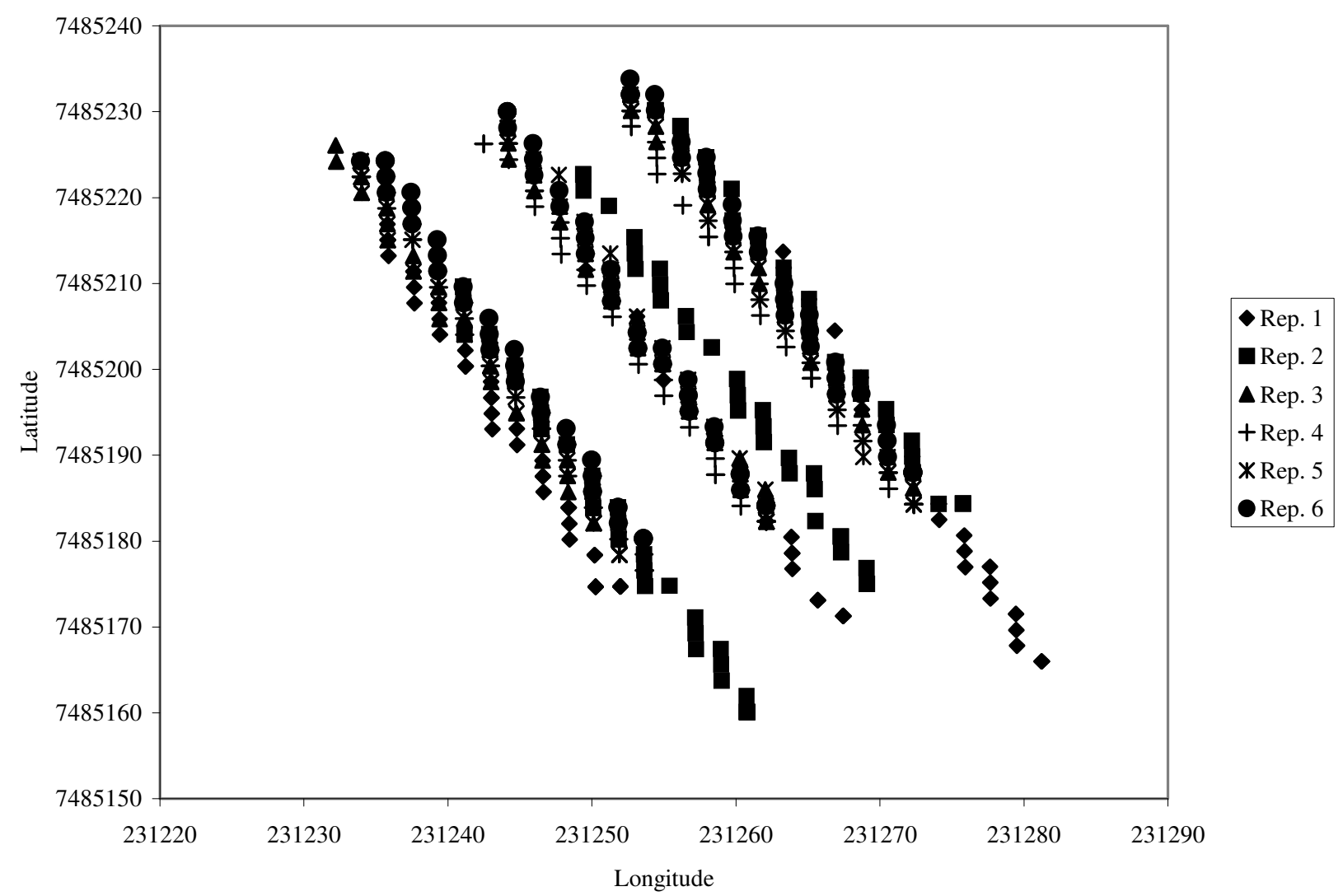

FIGURA 1. Gráfico das seis repetições GPS “A”, percorrendo três linhas de $50 \mathrm{~m}$ espaçadas $10 \mathrm{~m}$ entre si. Dia 25-09-2002, oito satélites em vista, PDOP máx. 4 (UTM Zona 23 Sul). 


\section{DGPS “B”}

O DGPS "B" mostrou alta uniformidade, ainda que inferior ao GPS "C". Seu custo inicial é bastante alto, uma vez que o sistema como um todo é composto de uma base de DGPS (GPS, interface para cálculo do sinal de correção e um rádio transmissor) e um receptor móvel com um rádio que recebe o sinal de correção diferencial. O coletor de dados desse sistema é o AgNavigator, que já é programado para aplicações agrícolas e coleta os dados em UTM, conforme se pode ver na Figura 2.

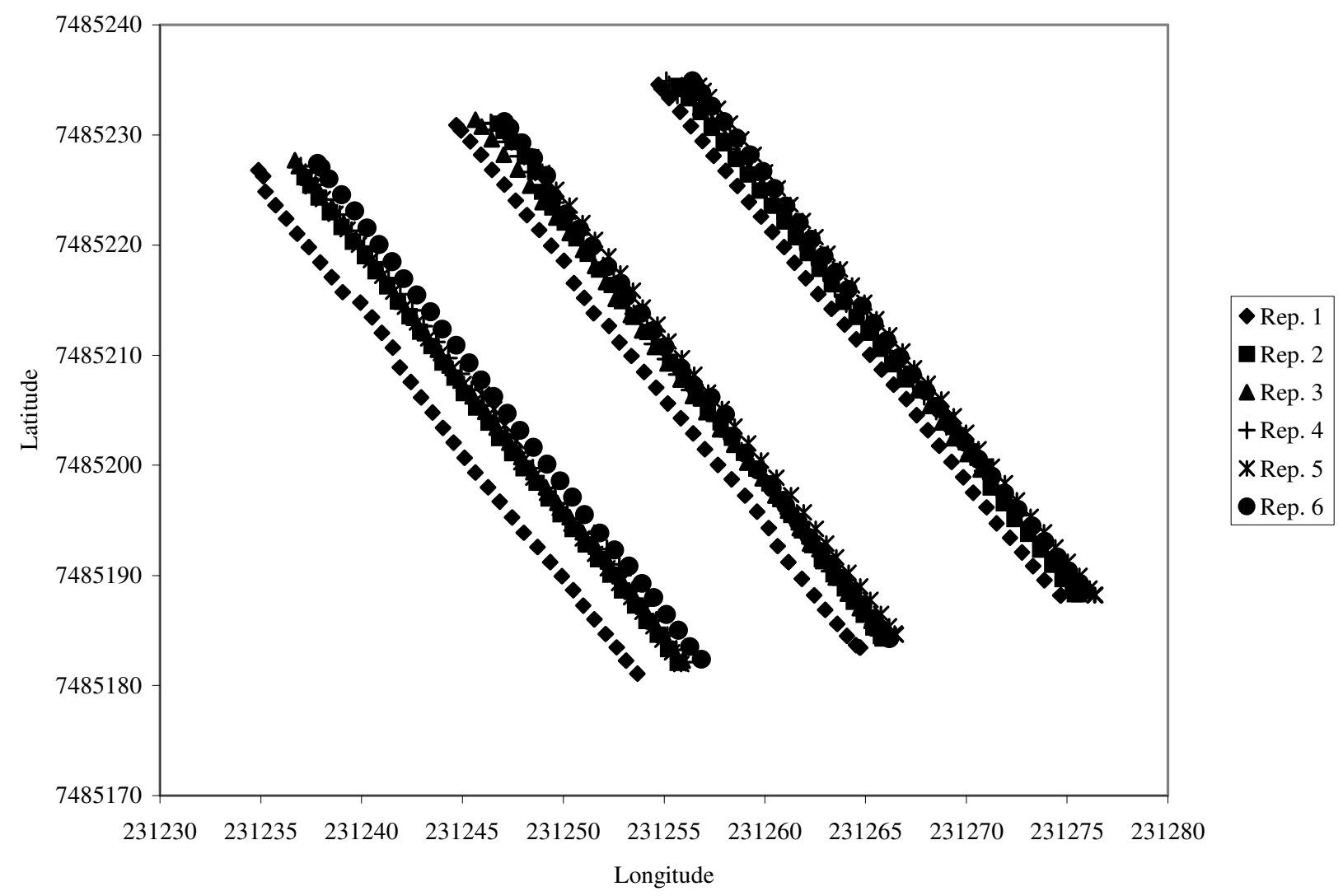

FIGURA 2. Gráfico de seis repetições do DGPS "B", percorrendo três linhas de $50 \mathrm{~m}$ espaçadas $10 \mathrm{~m}$ entre si. Dia 25-09-2002, oito satélites em vista, PDOP máx. 4 (UTM Zona 23 Sul).

\section{GPS "C"}

No campo experimental da ESALQ/USP, o GPS "C" mostrou alta linearidade, com o $\mathrm{R}^{2}$ da regressão acima de $99,7 \%$.

Pode-se comparar o comportamento de cada um dos GPSs na Figura 4, onde os dados foram convertidos para UTM, para facilitar a compreensão. As linhas sólidas representam as retas de regressão de cada conjunto de dados, podendo-se observar maiores variações para o DGPS “A”.

É necessário salientar que não é possível afirmar qual dos sistemas tem maior acurácia, uma vez que não se sabe de fato a localização real das linhas. O que se pode analisar é a acurácia e a repetibilidade dos dados, uma vez que aqueles coletados em datas diferentes e que se mostrem consistentes vão indicar maior acurácia e estabilidade do sistema como um todo. 


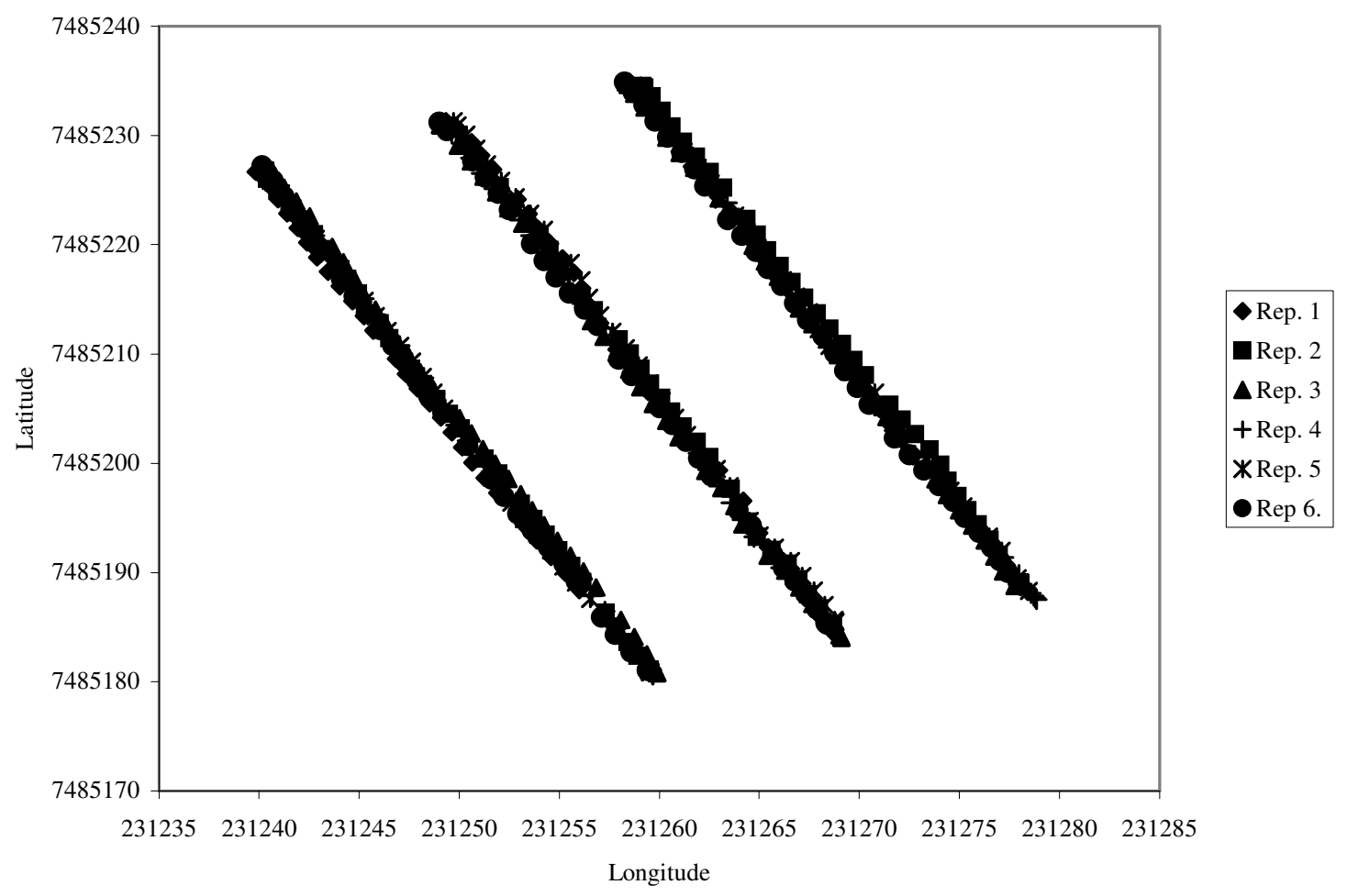

FIGURA 3. Gráfico de seis repetições do GPS "C", com algoritmo otimizado, percorrendo três linhas de 50 m espaçadas 10 m entre si. Dia 25-9-2002, oito satélites em vista, PDOP máx. 4 (UTM Zona $23 \mathrm{Sul}$ ).

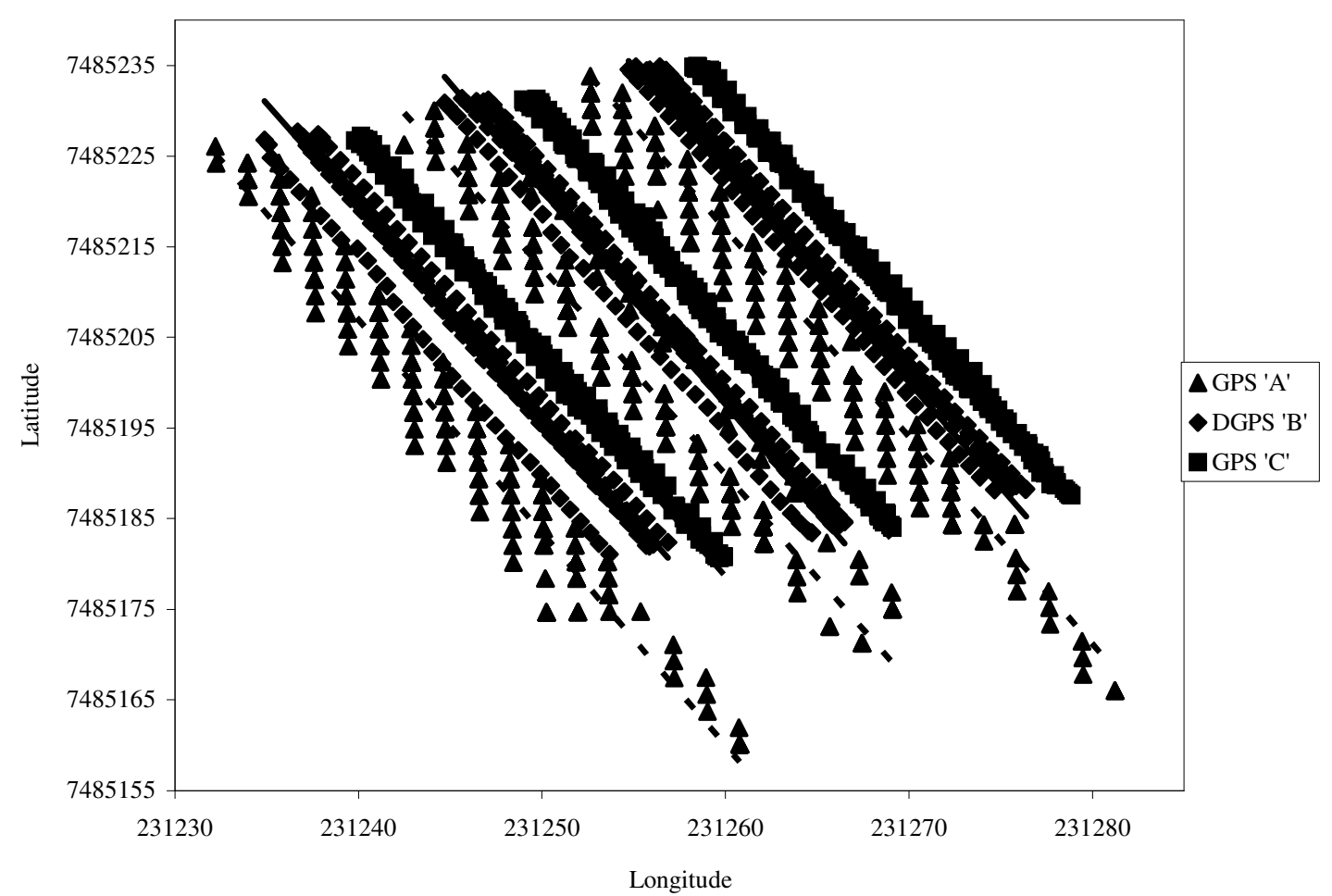

FIGURA 4. Comparação dos três GPSs "A", "B" e "C", no dia 25-09, com seis repetições de cada linha, PDOP máx. 4 e no mínimo oito satélites em vista (UTM Zona 23 Sul). 


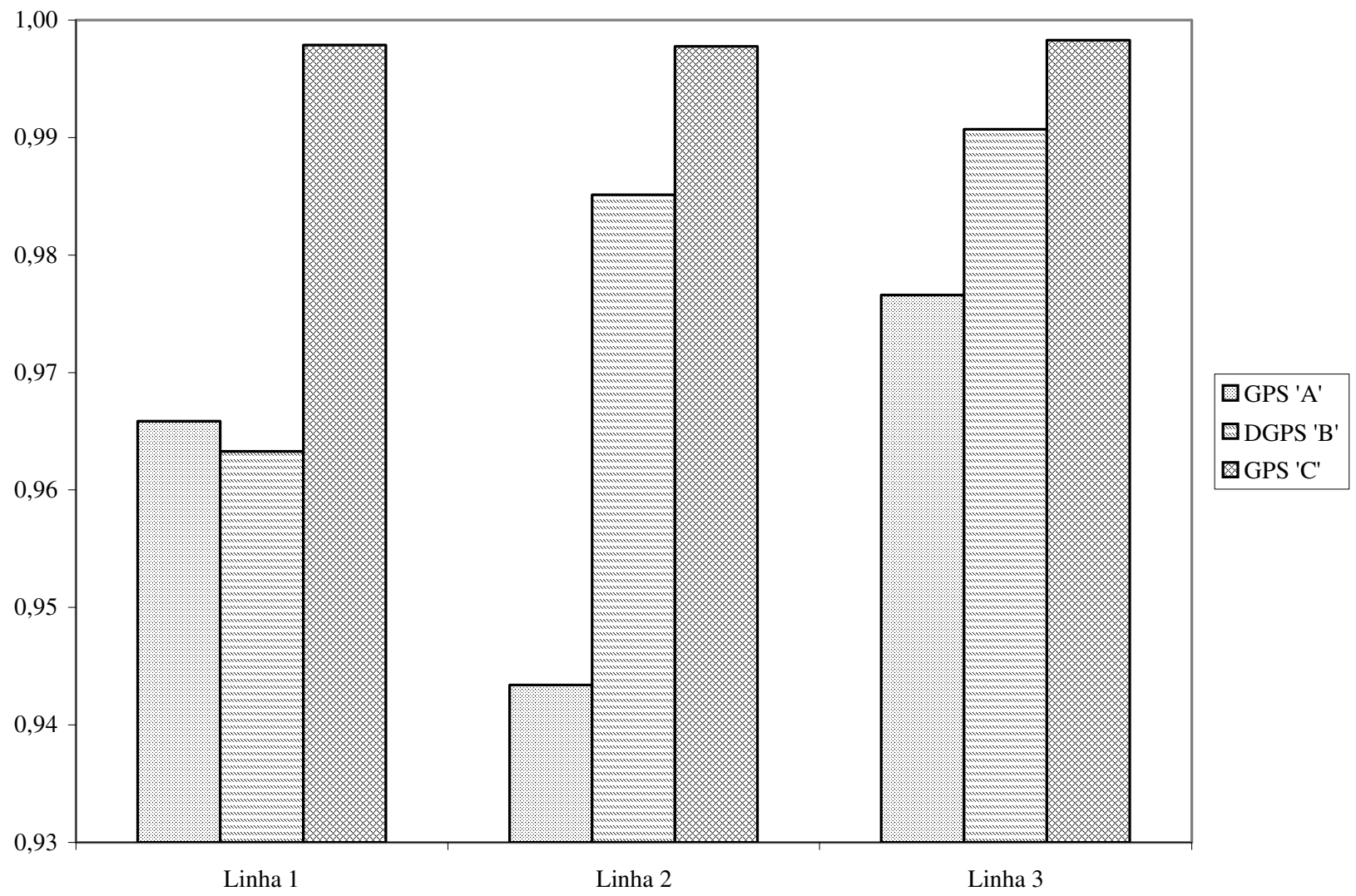

FIGURA 5. Coeficiente de regressão $\left(\mathrm{R}^{2}\right)$ para os três GPSs.

Como se pode observar, as retas de regressão se ajustam muito bem, mas a superioridade fica com os sistemas de DGPS e com o algoritmo otimizado. Pode-se observar que o $\mathrm{R}^{2}$ é acima de 94,0\% em todos os GPSs; o GPS "A" variando de 94,3 a 97,6\%, enquanto o DGPS "B" de 96,3 a 99,1\%, e o GPS "C" apresenta valores variando de 99,7 a $99,8 \%$. O $\mathrm{R}^{2}$ é utilizado para determinar quão bem os dados se ajustam a uma determinada equação; neste caso, apesar de todos os valores serem superiores a $94 \%$, os valores maiores indicam repetibilidade maior.

Os resíduos médios dos quadrados, por sua vez, representam a média dos quadrados dos erros, ponderados pelo número de dados. O GPS "A" apresentou maiores erros, da ordem de 6,6 a 14,2. O DGPS "B" apresentou erros variando de 2,1 a 7,1, enquanto no GPS "C" esses não passaram de 0,53. O quadrado dos erros em relação aos desvios da curva é minimizado com melhor encaixe da curva e, conseqüentemente, maior repetibilidade de dados.

Os desvios absolutos, em metros, de onde seria a reta de regressão computada pelos dados de cada GPS, foram medidos. Como podemos ver, o GPS "A" teve os maiores desvios (-9,2 a 9,7 m), enquanto o DGPS "B" teve desvios menores (-6,2 a 3,9 m) e o GPS "C" manteve os menores valores, com os desvios entre -1,7 e 1,7 m. Considerando-se que o experimento consistia de linhas paralelas de 50 m espaçadas $10 \mathrm{~m}$ entre si, o GPS "A" computou dados que desviavam da sua linha ideal quase a distância total entre as linhas no campo $(9,7 \mathrm{~m})$, e, portanto, os erros gerados pela utilização de seus dados comprometem o seu uso para a Agricultura de Precisão. 


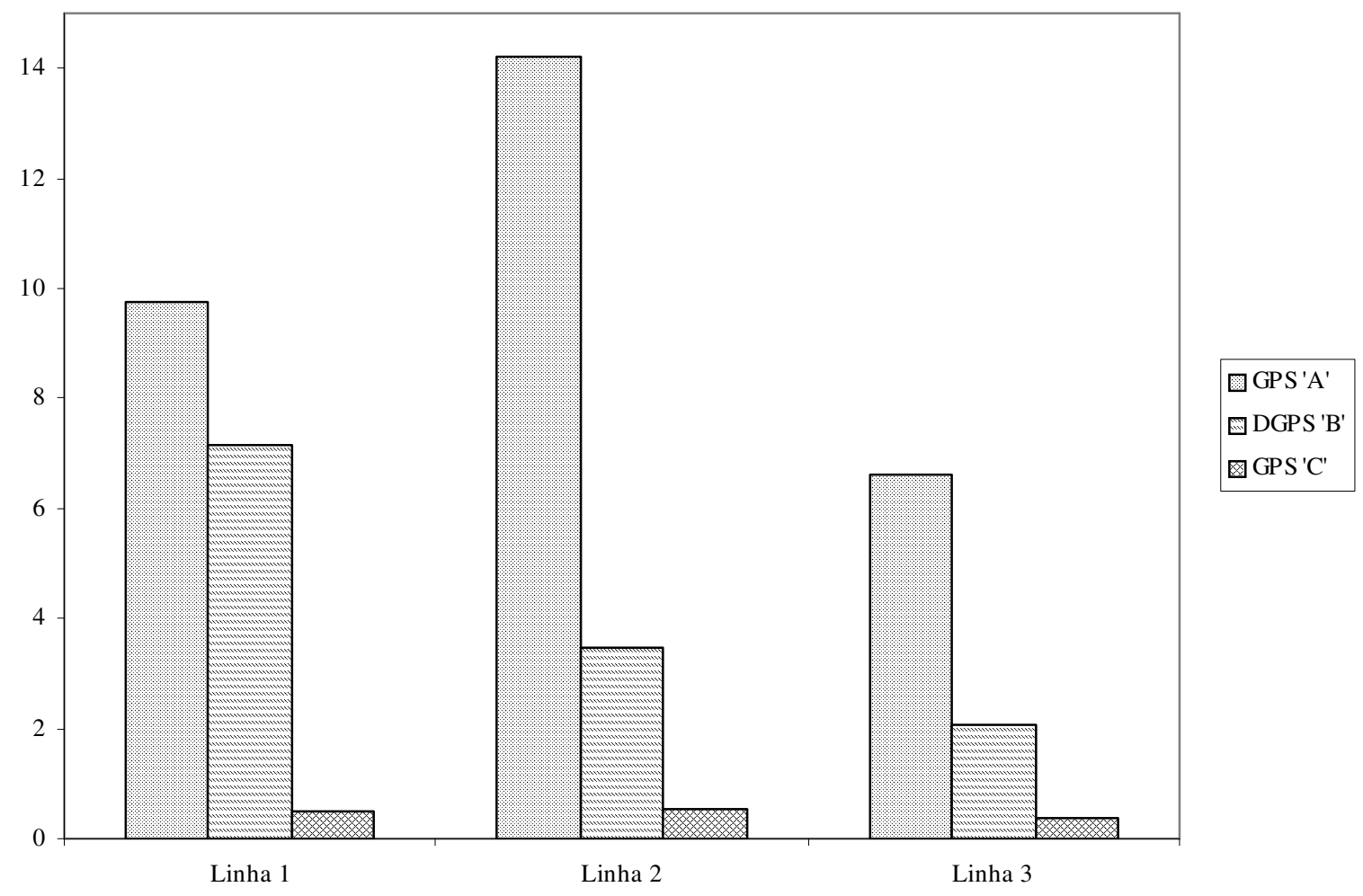

FIGURA 6. Quadrados médios dos três GPS's.

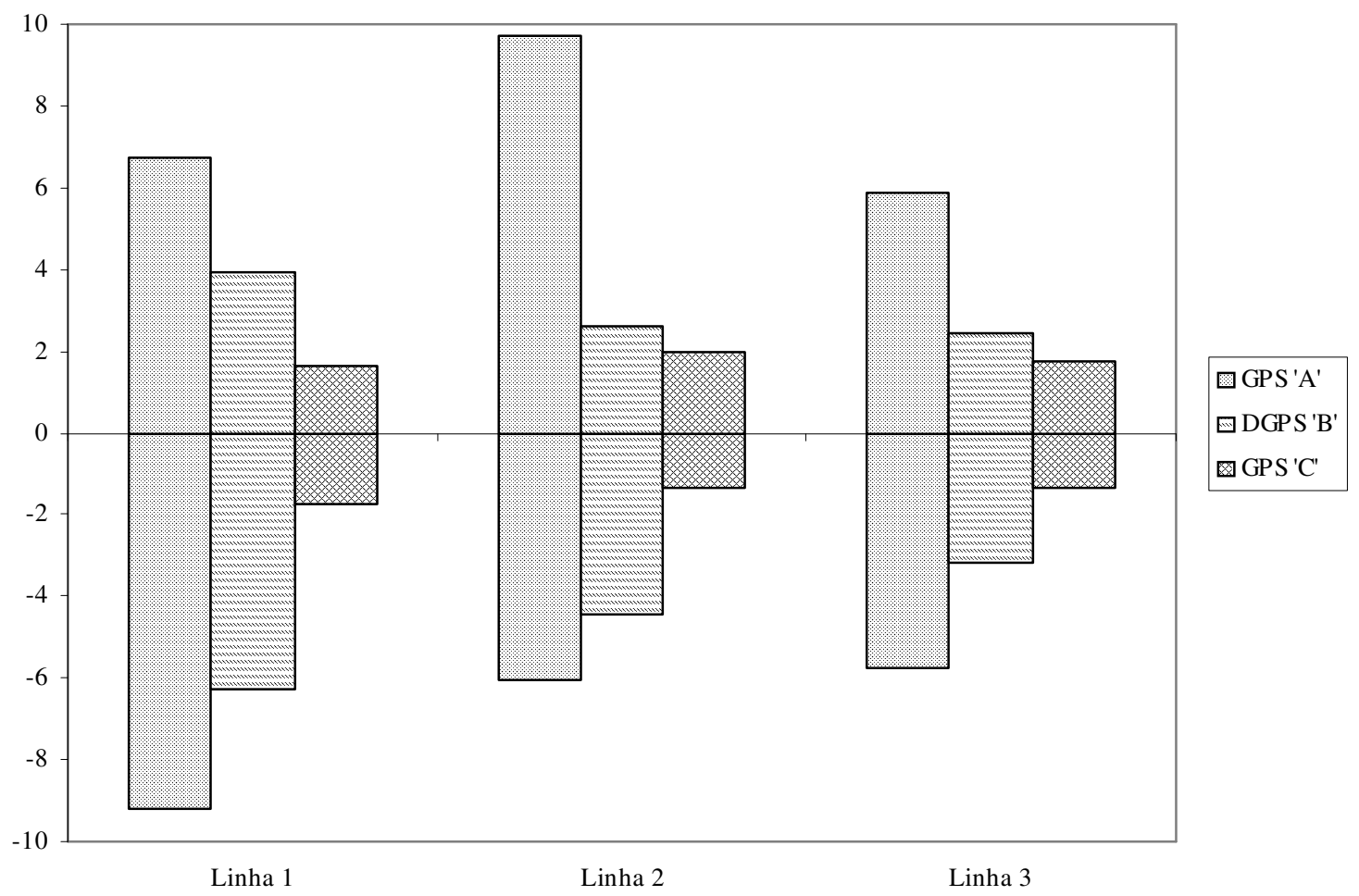

FIGURA 7. Desvios (m) em relação aos valores esperados das linhas. 


\section{CONCLUSÕES}

O que se pode concluir da análise e discussão dos dados, é a superioridade do algoritmo otimizado e do DGPS em relação ao GPS sem correção. Como um DGPS tem alto custo inicial, e um algoritmo otimizado não está disponível em todas as empresas fabricantes de equipamentos de GPS, uma alternativa para tornar mais viável a utilização dos conceitos da Agricultura de Precisão seria o desenvolvimento de um DGPS de baixo custo, utilizando-se de tecnologia nacional e que poderia ser utilizado por produtores rurais, com baixo custo inicial.

\section{REFERÊNCIAS}

BAIO, F.H.R.; ÂNGULO FILHO, R.; VETTORAZZI, C.A.; RAFFO, J.G.G.; ELIAS, A.I. Estudo da exatidão de um GPS operando em duas taxas de aquisição de dados. In: CONGRESSO BRASILEIRO DE ENGENHARIA AGRÍCOLA, 27., Poços de Caldas, 1998. Anais... Lavras: Sociedade Brasileira de Engenharia Agrícola, 1998. p.347-9.

BALASTREIRE, L.A. Avaliação do desempenho de um sistema de georreferenciamento portátil de baixo custo para Agricultura de Precisão. In: AVANÇOS NA AGRICULTURA DE PRECISÃO NO BRASIL NO PERÍODO DE 1999-2001, 2001, Piracicaba. Anais... Piracicaba: L.A. Balastreire, 2001. p.282-4.

BALASTREIRE, L.A.; BAIO, F.H.R. Avaliação do desempenho de um GPS com algoritmo otimizado sem sinal de correção para agricultura de precisão. In: AVANÇOS NA AGRICULTURA DE PRECISÃO NO BRASIL NO PERÍODO DE 1999-2001, 2001, Piracicaba. Anais... Piracicaba: L.A.Balastreire, 2001. p.285-8.

BLITZKOW, D. NAVSTAR/GPS: Um desafio tornado realidade. In: SIMPÓSIO BRASILEIRO DE GEOPROCESSAMENTO, 3., 1995, São Paulo. Anais... São Paulo: USP, 1995. p.429-62.

CASTRO, D.R.S. Breve descrição do GPS. Disponível em: <www.sistemasdearmas.hpg.ig.com.br/gpsdavi.htm>. Acesso em: fev. 2004.

GOERING, C.E.; HAN, S. A field information system for SSCM. Warrendale: SAE International, 1993. 13 p. (SAE Technical Paper Series, 932422)

HAN, S; HUMMEL, J.W; GOERING, C.E; CAHN, M.D. Cell size for site-specific crop management. Transactions of the ASAE, St. Joseph, v.37, n.1, p.19-26, jan./fev. 1994.

MORGAN, M. The precision-farming guide for agriculturists. Moline: Deere \& Company, 1997. $116 \mathrm{p}$.

PFOST, D.; CASADY, W.; SHANNON, K. Site-specific management guidelines 6: Global Positioning System Receivers, 2001. Disponível em: <www.ppi-far.org/ssmg>. Acesso em: fev. 2004.

REID J.F. Precision guidance for agricultural vehicles, 1998. Disponível em: $<$ http://www.age.uiuc.edu/oree/pdf/uilu-eng-98-7031.pdf>. Acesso em: fev. 2004

SEARCY, S. Special topics in precision agriculture: Lecture Notes, 2001. Disponível em: <www.agen.tamu.edu/txprecag/agsm489/>. Acesso em: fev. 2004. 